\title{
Perineural Way of Stem Cells Migration to Injured Heart Regions
}

\author{
Zamaro Aleksandra ${ }^{1}$, Koulchitsky Stanislav ${ }^{2}$, Pashkevich Svetlana ${ }^{1}$, Stukach Yulya ${ }^{1}$, Dosina Margarita ${ }^{1}$, \\ Kuznetsova Tatiana ${ }^{1}$, Hubkin Siarhei ${ }^{1}$, Filatova Daria ${ }^{1}$, Ablomeiko Antonina ${ }^{1}$, Bushuk Sergei ${ }^{3}$, \\ Kalvinkovskaya Julia ${ }^{3}$, Sushko Timur ${ }^{1}$, Gladkova Zhanna ${ }^{1}$, Shanko Yuri ${ }^{4}$ and Kulchitsky Vladimir*1 \\ ${ }^{1}$ Institute of Physiology, National Academy of Sciences, Belarus \\ ${ }^{2}$ Liege University, Liege, Belgium \\ ${ }^{3}$ B.I. Stepanov Institute of Physics, National Academy of Sciences, Minsk, Belarus
}

${ }^{4}$ Republican Scientific and Practical Center of Neurology and Neurosurgery, Minsk, Belarus

*Corresponding author: Kulchitsky Vladimir, Institute of Physiology, National Academy of Sciences, Belarus

\section{ARTICLE INFO}

Received: 㗀 January 30, 2019

Published: 幽 February 05, 2019

Citation: Zamaro A, Koulchitsky S, Pashkevich S, Stukach Y, Dosina M, Kuznetsova T, Hubkin S, Filatova D, Ablomeiko A, Bushuk S, Kalvinkovskaya J, Sushko T, Gladkova Z, Shanko Y, Kulchitsky V. Perineural Way of Stem Cells Migration to Injured Heart Regions. Biomed J Sci \& Tech Res 14(1)-2019. BJSTR. MS.ID.002496.

\section{ABSTRACT}

Hypothesis on reality of perineural migration of stem cells (SCs) along vagus nerve fibers to injured heart and brain stem regions was experimentally verified on ten Wistar rats. Heart injuries were simulated using unilateral vagotomy. Vagotomy led to degeneration of vagus nerve fibers in heart and brain stem. These destructive processes in tissues were the basis for SCs migration. FITC-labeled SCs were revealed in cardiac ganglions and nucleus tractus solitarii of brain stem. Experimental results should be used to test the technique in clinical conditions in patients with impaired cardiac function, namely with acute heart failure after myocardial infarction.

Abbreviations: FITC: Fluorescein isothiocyanate; NTS: Nucleus Tractus Solitarii; SCs: Stem cells

\section{Introduction}

Fatality of arrhythmias and heart failure is well known [1-4]. Despite existing threat to human life, intensive prophylaxis and therapy of pathological processes in heart and blood vessels begins only after diagnosis establishment. This stage of relationships between cardiologist and patient is currently in a good state. Classic therapy of heart failure includes range of cardiovascular drugs used in accordance with international guidelines [1,2]. Patients with terminal stage of heart failure are treated in intensive care units by infusions of inotropic agents. More radical treatment methods are used at certain stage of pathological processes development in heart. These include implantations of cardiac pacemakers, intracoronary balloon angioplasty, stenting of coronary vessels, coronary artery bypass graft surgery, valve replacement or implantation of artificial heart [1-4]. Angioplasty and stenting lead to decrease of mortality. Heart transplantation appears to be one of the most radical ways of therapy along with the development of technologies of organs and tissues transplantation [5]. Restrictions of transplantations are obvious, they include need of immunosuppression, which is accompanied with variety of side effects, and the lack of donor organs. All these, along with ethical issues, do not allow using heart transplantation in significant number of patients [1-5].

Cellular technologies are also implemented in the treatment of heart diseases [6-10]. Systemic or local administration of SCs into myocardium prevents injury of cardiac muscle caused by infarction [11-17]. SCs are usually administered in clinical conditions into systemic or coronary blood flow [14-21].

Technique of perineural implantation and migration of SCs attracts attention among other methods of SCs implantation [22]. Vagus nerve looks great in this scope due to its accessibility in simple 
surgical manipulation. By the way, electrostimulation of vagus nerve is used in cardiology to activate angiogenesis in myocardium [23]. For example, technique of perineural SCs implantation guarantees SCs delivery to the area of neurodestruction in brain or spinal cord using uncomplicated surgical methods [24-28]. Such minimally invasive tactics are actual for those patients who are in poor state, especially determined by heart failure. A hypothesis on the reality of vagosympathetic complex use as a kind of direct way of SCs delivery to heart atriums and ventricles was born to develop this direction. Analysis of scientific literature in PubMed on January 28, 2019 revealed only four and two articles on the search for "vagus stem cells infarct" and "vagus stem cells heart infarct", respectively. Authors of one article [23] paid attention to activation of angiogenesis processes in myocardium and enhancement of its contractility during stimulation of vagus nerve.

\section{Perineural Migration of SCs to Heart}

Clinical observations indicate that endogenous reparative potential of heart is often insufficient [1-4]. Therefore, it is necessary to develop technologies for increase of this potential. Minimally invasive and highly effective are the most promising ones. Authors pay attention to vagus nerve because its branches innervate sinoatrial and atrioventricular heart ganglions and myocardium of heart ventricles. SCs are able to migrate along cranial nerve fibers to damaged tissues, that is why it was assumed, similar to previously obtained results [24-28], that SCs will begin moving to that heart region which has injury.

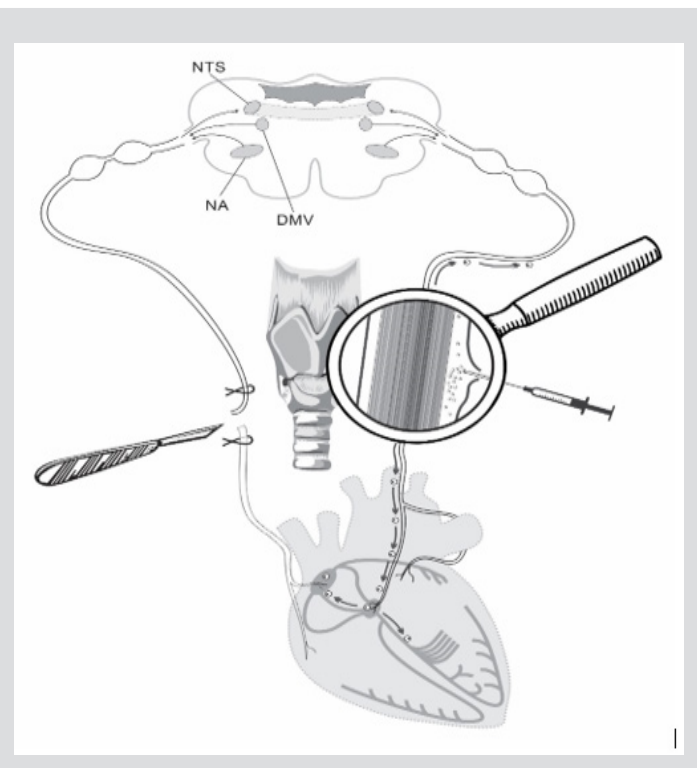

Figure 1: Scheme of unilateral vagotomy and perineural implantation of SCs into intact vagus nerve on the other side. Explained in text.

Ten adults male Wistar rats, weighing $200 \pm 230 \mathrm{~g}$ at the time of the experiments have been chosen to verify the hypothesis. Vagotomy (10 rats) was performed under ketamine-xylazineacepromazine anesthesia (55.6, 6.6 and $1.1 \mathrm{mg} / \mathrm{kg}$, respectively, i/p). All vagotomies were performed unilaterally at the cervical mid- level of neck (Figure 1). Simultaneously five rats received 10 thousand SCs in $10.0 \mu \mathrm{l}$ of culture medium into perineural space of another vagus (Figure 1). SCs have been stained for monoclonal antibodies to FITC-labeled CD90 (or to PKH67 Green Fluorescent Cell Linker). Authors assumed that unilateral vagotomy will lead to development of destructive processes in vagus endings in heart and brain stem nuclei and signaling molecules will be produced in damaged areas [22,24-26,28] to attract SCs. Figure 2 shows distribution of FITC-labeled SCs in the area of sinoatrial ganglion. Revealed FITC-labeled SCs in the area of heart automatism ganglion (Figure 2) in one day after vagotomy prove phenomenon of SCs perineural migration to destructed vagus sites in heart after their implantation into perineural space.

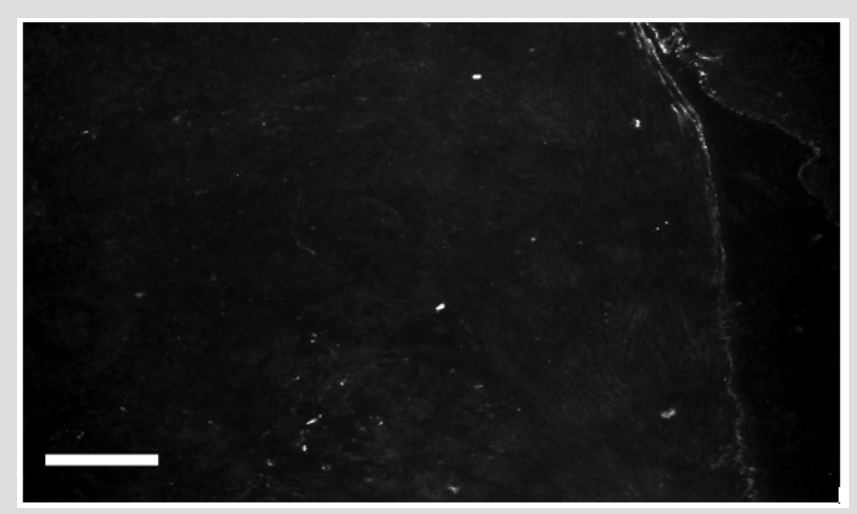

Figure 2: Distribution of CD90- and FITC-labeled SCs in the area of sinoatrial ganglion of rat. Bar - $100 \mu \mathrm{m}$. Explained in text.

\section{Perineural Migration of SCs to Brain}

Figure 3 shows distribution of FITC-labeled SCs in nucleus tractus solitarii (NTS). Appearance of SCs in brain stem can be explained from the point of wide allocation of vagus fibers in brain stem nuclei. Dorsal motor nucleus (DMV, Figure 1) together with nucleus ambiguous (NA) are also central representatives of vagus, besides NTS (Figure 1).

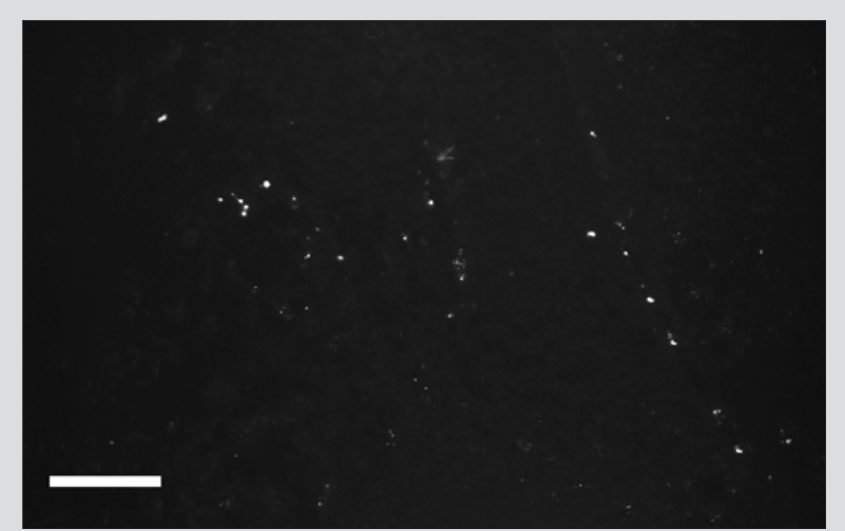

Figure 3: Distribution of CD90- and FITC-labeled SCs in the area of NTS of rat. Bar $-100 \mu \mathrm{m}$. Explained in text. 


\section{Conclusion}

Hypothesis on reality of perineural migration of SCs along vagus nerve fibers to injured heart regions was experimentally verified for the first time. Heart injuries were simulated using unilateral vagotomy on experimental rats. FITC-labeled SCs were revealed in cardiac ganglions and nucleus tractus solitarii of brain stem in one day after vagotomy. Experimental results should be used to test the technique in clinical conditions in patients with impaired cardiac function. Authors consider that special attention should be paid to described technique of perineural migration as supplementary procedure in acute period of heart failure development. It is advised to combine this technique with classic methods of heart failure therapy.

\section{Acknowledgement}

This pooled analysis was funded by 000 "Synergy", and by innovative fund of Brest Regional Executive Committee (2017-2019).

\section{References}

1. Teixeira RDS, Veras BMG, Senna KMSE, Caetano R (2018) Efficacy and Safety of PARACHUTE® Device: systematic review. Rev Assoc Med Bras (1992) 64(9): 853-860.

2. Koehler F, Koehler K, Deckwart O, Prescher S, Wegscheider K, et al. (2018) Telemedical Interventional Management in Heart Failure II (TIM-HF2), a randomised, controlled trial investigating the impact of telemedicine on unplanned cardiovascular hospitalisations and mortality in heart failure patients: Study design and description of the intervention. Eur J Heart Fail 20(10): 1485-1493.

3. Bonello L, Delmas C, Schurtz G, Leurent G, Bonnefoy E, et al. (2018) Mechanical circulatory support in patients with cardiogenic shock in intensive care units: A position paper of the "Unité de Soins Intensifs de Cardiologie" group of the French Society of Cardiology, endorsed by the "Groupe Athérome et Cardiologie Interventionnelle" of the French Society of Cardiology. Arch Cardiovasc Dis 111(10): 601-612.

4. Randhawa VK, Grunau BE, Debicki DB, Zhou J, Hegazy AF, et al. (2018) Cardiac Intensive Care Unit Management of Patients After Cardiac Arrest: Now the Real Work Begins. Can J Cardiol 34(2): 156-167.

5. Dimopoulos K, Muthiah K, Alonso-Gonzalez R, Banner NR, Wort SJ, et al. (2019) Heart or heart-lung transplantation for patients with congenital heart disease in England. Heart: pii: heartjnl-2018-313984.

6. Sanz-Ruiz R, Fernández-Avilés F (2018) Autologous and allogeneic cardiac stem cell therapy for cardiovascular diseases. Pharmacol Res 127: 92-100.

7. Chen SL, Fang WW, Ye F, Liu YH, Qian J, et al. (2004) Effect on left ventricular function of intracoronary transplantation of autologous bone marrow mesenchymal stem cell in patients with acute myocardial infarction. Am J Cardiol 94(1): 92-95.

8. Bartunek J, Dimmeler S, Drexler H, Frenandez-Aviles F, Gallinares M, et al. (2006) The consensus of the task force of the European Society of Cardiology concerning the clinical investigation of the use of autologous adult stem cells for repair of the heart. Eur Heart J 27(11): 1338-1340.

9. Tendera M (2008) Myocardial regeneration by intracoronary infusion of selected population of stem cells in acute myocardial infarction (REGENT) randomized multicenter trial. Clin Res Cardiol 97(12): 853.

10. Mansour S, Roy DC, Bouchard V, Nguyen BK, Stevens LM, et al. (2010) COMPARE-AMI trial: Comparison of intracoronary injection of CD133+ bone marrow stem cells to placebo in patients after acute myocardial infarction and left ventricular dysfunction: study rationale and design. J Cardiovasc Transl Res 3(2): 153-159.

11. Angeli FS, Caramori PR, da Costa Escobar Piccoli J, Danzmann LC, Magedanz E, et al. (2012) Autologus transplantation of mononuclear bone marrow cells after acute myocardial infarction: A PILOT study. Inter J Cardiol 158(3): 449-450.

12. Heeger CH, Jaquet K, Thiele H, Zulkarnaen Y, Cuneo A, et al. (2012) Percutaneous, transendocardial injection of bone marrow-derived mononuclear cells in heart failure patients following acute ST-elevation myocardial infarction: ALSTER-Stem Cell trial. Eurointervention 8(6): 732-742.

13. Chen XM, Cui DY, Zhang M (2014) Clinical observation of stem cell transplantation in patients with acute myocardial infarction complicated with heart failure. J Dalian Med Univer 36(2): 157-159.

14. Delewi R, Hirsch A, Tijssen JG, Schächinger V, Wojakowski W, et al. (2014) Impact of intracoronary bone marrow cell therapy on left ventricular function in the setting of ST-segment elevation myocardial infarction: A collaborative meta-analysis. Eur Heart J 35(15): 989-998.

15. Silva T, Fiarresga A, Abreu J, Reffeira A, Branco L, et al. (2014) Effect of intracoronary infusion of autologous bone marrow derived progenitor cells on the global longitudinal strain in patients with ST-elevation myocardial infarction. Eur Heart J 35: 306.

16. Wang X, Xi WC, Wang F (2014) The beneficial effects of intracoronary autologous bone marrow stem cell transfer as an adjunct to percutaneous coronary intervention in patients with acute myocardial infarction. Biotech Lett 36 (11): 2163-2168.

17. Yu L, Zhang M (2014) Intracoronary transplantation of autologous peripheral blood stem cells in old patients with acute myocardial infarction: Five-year postoperative evaluation of cardiac function. Cn J Tissue Eng Res 18(1): 125-130.

18. Behfar A, Crespo-Diaz R, Terzic A, Gersh BJ (2014) Cell therapy for cardiac repair--lessons from clinical trials. Nat Rev Cardiol 11(4): 232246.

19. Fisher SA, Doree C, Mathur A, Martin-Rendon E (2015) Meta-analysis of cell therapy trials for patients with heart failure. Circul Res 116(8): 1361-1377.

20. Gyöngyösi M, Wojakowski W, Lemarchand P, Lunde K, Tendera M, et al. (2015) Meta-Analysis of Cell-based CaRdiac stUdiEs (ACCRUE) in patients with acute myocardial infarction based on individual patient data. Circul Res 116(8): 1346-1360.

21. Hu X, Huang X, Yang Q Wang L, Sun J, et al. (2015) Safety and efficacy of intracoronary hypoxia-preconditioned bone marrow mononuclear cell administration for acute myocardial infarction patients: the CHINA-AMI randomized controlled trial. Inter J Cardiol 184: 446-451.

22. Kulchitsky V, Zamaro A, Shanko Y, Koulchitsky S (2018) Prospects of Perineural Implantation of Stem Cells in Recovery of Neural Networks' Functions in Brain Diseases. Biomed J Sci\&Tech Res 10(3): 1-4.

23. Lv YX, Zhong S, Tang H, Luo B, Chen SJ, et al. (2018) VEGF-A and VEGF-B Coordinate the Arteriogenesis to Repair the Infarcted Heart with Vagus Nerve Stimulation. Cell Physiol Biochem 48(2): 433-449.

24. Shanko Y, Zamaro A, Takalchik-Stukach Y, Koulchitsky S, Pashkevich S, et al. (2018) Mechanisms of Neural Network Structures Recovery in Brain Trauma. Biomed J Sci\&Tech Res 7(5): 1-2.

25. Shanko Y, Navitskaya V, Zamaro A, Krivenko S, Zafranskaya M, et al. (2018) Prospects of Perineural Administration of Autologous Mesenchymal Stem Cells of Adipose Tissue in Patients with Cerebral Infarction. Biomed J Sci\&Tech Res 10(1): 1-3.

26. Shanko Y, Navitskaya V, Zamaro A, Zafranskaya M, Krivenko S, et al. (2018) Somatotopic principle of perineural implantation of stem cells in patients with brain injuries. J Neurol Stroke 8(5): 259-261.

27. Kulchitsky V, Zamaro A, Pashkevich S, Sushko T, Koulchitsky S (2018) Nasolacrimal way of stem cells implantation. J Neurol Stroke 8(2): 110111.

28. Kulchitsky V, Zamaro A, Shanko Y, Koulchitsky S (2018) Positive and negative aspects of cell technologies in cerebral diseases. J Neurol Stroke 8(2): 87-88. 


\section{ISSN: 2574-1241}

DOI: 10.26717.BJSTR.2019.14.002496

Kulchitsky Vladimir.Biomed J Sci \& Tech Res

(C) This work is licensed under Creative

Submission Link: https://biomedres.us/submit-manuscript.php

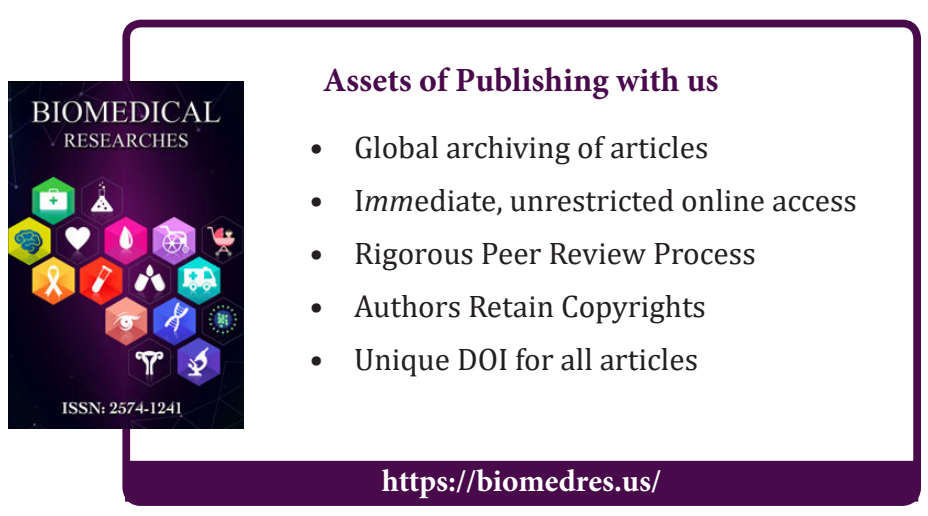

